\title{
Erratum to: Skin collagen advanced glycation endproducts (AGEs) and the long-term progression of sub-clinical cardiovascular disease in type 1 diabetes
}

Vincent M Monnier ${ }^{1,2^{*}}$, Wanjie Sun ${ }^{3}$, Xiaoyu Gao ${ }^{3}$, David R Sell ${ }^{1}$, Patricia A Cleary ${ }^{3}$, John M Lachin ${ }^{3}$, Saul Genuth ${ }^{4}$ and The DCCT/EDIC Research Group ${ }^{5}$

\section{Erratum to: Cardiovasc Diabetol (2015) 14:118 DOI 10.1186/s12933-015-0266-4}

After publication of the original article it came to the authors' attention that there was an error in the 'Results' section of the abstract. The value ' 0.39 ' should have been given as ' 0.039 '. This error has now been corrected in the original article.
The online version of the original article can be found under doi:10.1186/s12933-015-0266-4.

Received: 22 September 2015 Accepted: 22 September 2015

Published online: 09 October 2015

\section{Author details}

1 Departments of Pathology, Case Western Reserve University School of Medicine, Cleveland, OH, USA. ${ }^{2}$ Departments of Biochemistry, Case Western Reserve University School of Medicine, Cleveland, OH, USA. ${ }^{3}$ The Biostatistics Center, The George Washington University, Rockville, MD, USA. ${ }^{4}$ Department of Medicine, Case Western Reserve University School of Medicine, Cleveland, OH, USA. ${ }^{5}$ http://www.diabetes.niddk.nih.gov/dm/pubs/control/.

*Correspondence: vmm3@cwru.edu

1 Departments of Pathology, Case Western Reserve University School

of Medicine, Cleveland, OH, USA

Full list of author information is available at the end of the article 